\title{
High Exergetic Modified Brayton Cycle with Thermoelectric Energy Conversion
}

\author{
Kazuaki Yazawa $^{\mathrm{a}}$, Timothy S. Fisher ${ }^{\mathrm{a}, \mathrm{b}}$, Eckhard A. Groll ${ }^{\mathrm{b}}$, and Ali Shakouri ${ }^{\mathrm{a}}$ \\ ${ }^{a}$ Birck Nanotechnology Center, Purdue University \\ ${ }^{b}$ Department of Mechanical Engineering, Purdue University
}

\begin{abstract}
A novel concept using thermoelectric direct power generators (TEGs) integrated into a 1 $\mathrm{kW}$ scale miniature Brayton cycle is investigated based on an analytical study. The work considers a residential scale application aiming to achieve $40 \%$ primary energy efficiency in contrast to the state-of-the-art miniature gas turbine alone, which can only achieve $<16 \%$. A topping cycle TEG for a hot gas temperature at $1600-1700^{\circ} \mathrm{C}$ is embedded in the combustor scale of a kitchen stove. This TEG converts a fraction of the heat into electricity, while all the remaining thermal energy proceeds to the Brayton cycle. Turbine-inlet gas temperature regulates to $800-1100^{\circ} \mathrm{C}$ by optimizing the air mixture. A second TEG is built in the recuperator; hence, the associated temperature is similar to that of a vehicle exhaust. A third TEG is used for waste heat recovery from flue gas, and then the downstream heat flow is used by a combined-heat-power system. By taking advantage of low-profile modules, the TEG embedded heat exchanges can be compact and low-cost at 0.2-0.3 \$/W. The figure-of-merit of the thermoelectric materials considers ZT $1.0-1.8$. Assuming that all advanced components are utilized, the primary energy efficiency predicts $42 \%$ with power output $720 \mathrm{~W}$ from the alternator and $325 \mathrm{~W}$ from the TEGs out of $0.456 \mathrm{~g} / \mathrm{s}$ of a pipeline natural gas input.
\end{abstract}

\section{Corresponding author:}

\section{Kazuaki Yazawa}

Address: 1205 W. State St., West Lafayette, IN 47907

Email: kyazawa@purdue.edu 


\section{Keywords:}

modified Brayton cycle, topping cycle, thermoelectric generator, recuperator, figure-ofmerit

\section{Graphical abstract:}

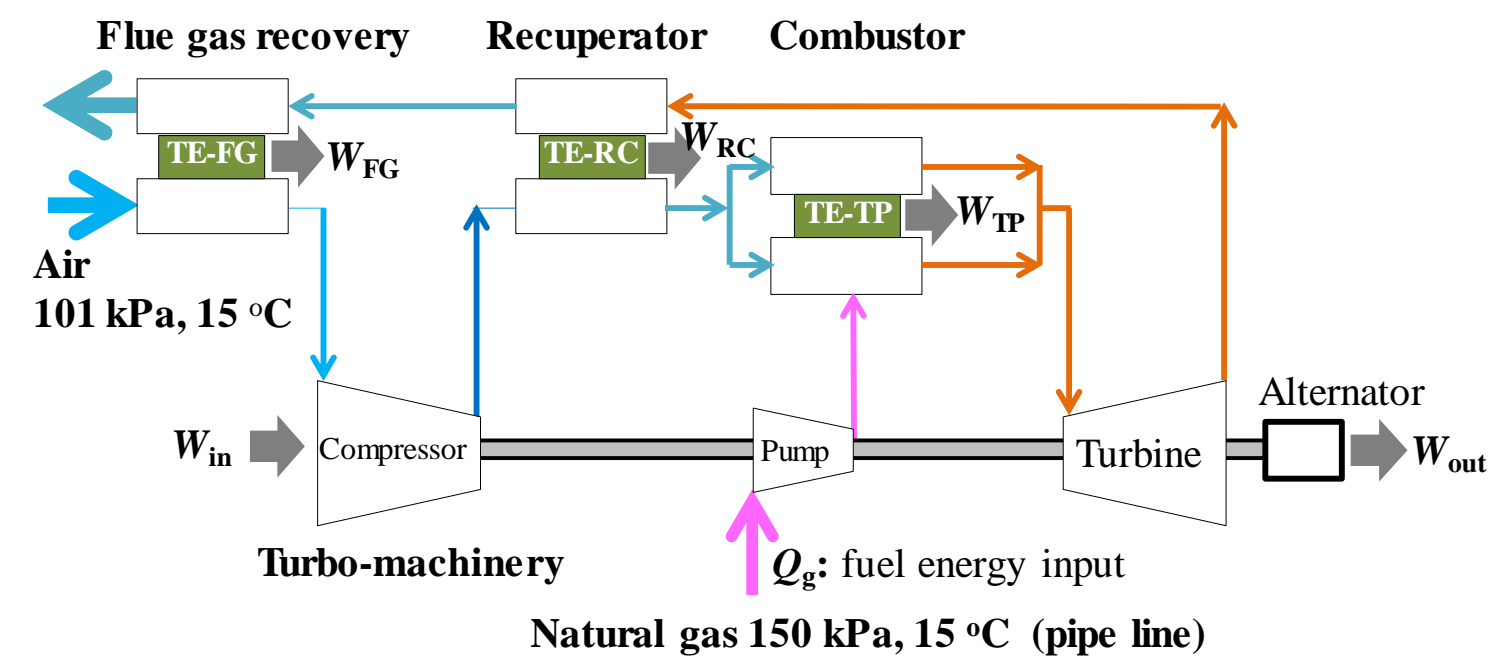

\section{Introduction}

Among the miniature scale Brayton cycles with 1-10 kW output range, a study by Visser et al. [1] reported that the performance of a state-of-the-art recuperative Brayton cycle reached only $16 \%$. Our preliminary thermodynamic simulation with an analytic model revealed a similar percentage using a model based on Engineering Equation Solver (EES) software, but this simulation had a slightly higher efficiency of $17.3 \%$ for the same conditions. We investigate and analyze here the system performance, which integrates multiple thermoelectric generators (TEGs) into a recuperative Brayton cycle. The target performance is $40 \%$ power efficiency from the chemical potential of natural gas while considering a compact form factor, i.e., a 50-liter box.

Three TEGs are considered. The first one is in the combustor in which a large temperature gap exists between the frame and the hot gas allowed to flow in the turbine. The second TEG is embedded in the recuperator, and the third one is designed for flue gas waste heat 
recovery. Thermoelectric generators are designed to be optimum based on our model [2] and considering the currently available state-of-the-art thermoelectric materials, whose figure-of-merit (ZT) values are 0.8 - 1.2 depending on the temperature range. The results project the overall efficiency to be $28.7 \%$.

Separating TEGs for different and narrower temperature ranges allows us to choose thermoelectric materials that are optimal for the highest average ZT value. By developing a technology for advanced TEG module integrated heat exchangers with state-of-the-art thermoelectric materials, the efficiency can increase considerably. What-if analyses are carried out to assess whether the efficiency target is achievable considering further improvements in isentropic efficiencies of the mechanical components, i.e., compressor, pump, and turbine, while the alternator efficiency can be slightly lower, e.g. 0.9, for cost effectiveness.

A complete schematic of the system is shown in Fig.1, and it is similar to a recuperative Brayton cycle. Natural gas is the fuel, with a supply pressure of $150 \mathrm{kPa}$ (1.5 bar) at a temperature of $15^{\circ} \mathrm{C}$. The chemical potential of natural gas is assumed to be the standard value of Higher Heating Value of $36.6 \mathrm{MJ} / \mathrm{m}^{3}\left(983 \mathrm{Btu} / \mathrm{ft}^{3}\right)$ according to the US Department of Energy [3]. To provide $2.5 \mathrm{~kW}$ energy of fuel to the system, the volumetric flow rate must be $6.83 \times 10^{-4} \mathrm{~m}^{3} / \mathrm{s}$, while the mass flow rate is $0.456 \mathrm{~g} / \mathrm{s}$ assuming a gas density of $0.668 \mathrm{~kg} / \mathrm{m}^{3}$.

As the natural gas enters the combustor by pressurizing with a pump, it burns by being optimally mixed with compressed and pre-heated fresh air. The air inflow is divided between the combustion chamber and another chamber to create a temperature difference across the embedded TEG. The mixture flow of exhausts of both of the above comes into the turbine. The gas temperature flowing into the turbine is a key control parameter, so the TEG is designed to match the flow rates and temperatures of the two flow passages. The gas returned from the turbine goes through the recuperator and exchanges heat to pre-heat the fresh air. The second TEG is co-designed with the heat exchanger. The flue gas flows through another heat exchanger to recover the heat from the flue gas with temperatures up to $180^{\circ} \mathrm{C}$.

Thermoelectric material properties play a significant role in the conversion efficiency at the 
maximum power output. Table 1 shows the values that are used in the calculation for case 1: currently available on the market and case 2 : potential materials available years in the future. It is investigated how future thermoelectric materials with higher ZT values will impact the overall system energy efficiency. In the analysis, the temperature ranges are set desirable for the recuperated Brayton cycle. The thermoelectric modules are then designed to match the optimum for three individual locations, the combustor, recuperator, and flue gas recovery sections. The remaining exit gas temperature is still able to heat the tap water, so another $40 \%$ of the heat energy can be used for space heating or supplying hot water.

\section{System concept and efficiencies}

\section{SYSTEM MODELING}

We calculated the efficiency of the recuperated Brayton cycle using a cycle analysis model built on the software EES [4]. The mechanical work output from the turbine, subtracting the pump work and compressor work, is the net output from the Brayton cycle. The recuperator recovers heat from the turbine outlet by a heat exchanger built-in, where a thermoelectric module comes in. If no TEG is implemented with perfect isentropic efficiency for the turbine and compressor, the net efficiency $\eta$ of a standard Brayton cycle is,

$$
\eta=1-\frac{1}{r_{p}^{(k-1) k}}
$$

where, $r_{\mathrm{p}}$ is compression ratio and $k$ is the specific heat ratio $k=C_{\mathrm{p}} / C_{\mathrm{v}}$. The power output from the TEG is separately determined from the above model but is based on an analytic model. All TEG designs are based on a condition that achieves the maximum power output (not the maximum efficiency) to minimize the spatial and cost impacts of the TEG integration. Based on previous work, the temperature delta optimum is nearly half the entire temperature difference between the hot and cold gas temperatures.

The system efficiency $\eta_{\text {sys }}$ is a function of electrical power $W_{\text {sys }}$ and chemical energy input $Q_{\mathrm{g}}$ as

$$
\eta_{\text {sys }}=\left(\frac{W_{\text {sys }}}{Q_{\mathrm{g}}}\right)
$$


where,

$$
\begin{aligned}
& W_{\text {sys }}=\left(W_{\mathrm{TP}}+W_{\mathrm{RC}}+W_{\mathrm{FG}}\right)+\eta_{\mathrm{A}}\left(W_{\text {out }}-W_{\text {in }}\right) \\
& W_{\mathrm{TP}}=\eta_{\mathrm{TE}-\mathrm{TP}} \eta_{\mathrm{N}} Q_{\mathrm{g}} \\
& W_{\text {out }}=\eta_{\mathrm{T}} \eta_{\mathrm{TD}}\left(1-\eta_{\mathrm{TE}-\mathrm{TP}}\right) \eta_{\mathrm{N}} Q_{\mathrm{g}} \\
& W_{\mathrm{RC}}=\eta_{\mathrm{TE}-\mathrm{RC}}\left(1-\eta_{\mathrm{TD}}\right)\left(1-\eta_{\mathrm{TE}-\mathrm{TP}}\right) \eta_{\mathrm{N}} Q_{\mathrm{g}} \\
& W_{\mathrm{FG}}=\eta_{\mathrm{TE}-\mathrm{FG}}\left(1-\eta_{\mathrm{TE}-\mathrm{RC}}\right)\left(1-\eta_{\mathrm{TD}}\right)\left(1-\eta_{\mathrm{TE}-\mathrm{TP}}\right) \eta_{\mathrm{N}} Q_{\mathrm{g}} \\
& W_{\text {in }}=W_{\mathrm{P}} / \eta_{\mathrm{p}}+W_{\mathrm{C}} / \eta_{\mathrm{C}} \approx W_{\mathrm{C}} / \eta_{\mathrm{C}}
\end{aligned}
$$

where, $\eta_{\mathrm{N}}$ is combustion efficiency, $\eta_{\mathrm{TD}}$ is thermodynamic efficiency for a turbine, $\eta_{\mathrm{T}}$ is electro-mechanical efficiency of an alternator, $\eta_{\mathrm{C}}$ is compressor isentropic efficiency, $\eta_{\mathrm{P}}$ is fuel pump isentropic efficiency, and $\eta_{\mathrm{A}}$ is alternator efficiency. $W_{\text {out }}$ is the turbine work out and $W_{\text {in }}$ is the sum of the needed work for the turbine compressor $W_{\mathrm{c}}$ and the fuel pump $W_{\mathrm{p}}$. $W_{\mathrm{TP}}, W_{\mathrm{RC}}$, and $W_{\mathrm{RC}}$ are power outputs from the thermoelectric generators placed in the combustor, recuperator, and the flue gas exhaust, respectively. The efficiencies of thermoelectric energy conversion are noted as $\eta_{\mathrm{TE}-\mathrm{TP}}, \eta_{\mathrm{TE}-\mathrm{RC}}$, and $\eta_{\mathrm{TE}-\mathrm{FG}}$, respectively. These efficiencies are calculated at the maximum power output with optimally designed thermoelectric modules based on given external temperature conditions shown in the next section. Note that the power output from TEGs is naturally DC and from the alternator is AC. Thermodynamic efficiency is built into the efficiency of the TEG module. In this study, we calculate only the power and do not distinguish among the applications which use the generated power.

\section{Thermoelectric generator}

\subsection{TEG optimization}

The TEG in this study plays a significant role in achieving higher system efficiency for miniaturizing compared to that of a conventional Brayton cycle. High temperature TEG 
devices have been used in space applications by NASA JPL, such as [5] and [6]. The thermoelectric materials for the temperature range over $900^{\circ} \mathrm{C}$ requiring a technological breakthrough in the stability of the material properties due to the higher possibility of a chemical reaction, such as atomic diffusion. The stability of the mechanical structures due to mechanical stress according to the thermal expansion is also a concern. This study assumes that the above technical challenge will be cleared up with further research and development.

Most TEGs consist of p-type and n-type semiconductor materials as the elements. The TEG module is built in $\pi$-shape arrangement of the elements, where the elements are electrically connected in series and thermally placed parallel to the heat flow.

Since both electrical and thermal energy flows are combined into the simple brick geometry of the thermoelectric element, both energy flows are deeply dependent. We carried out a generic analytic modeling for the thermoelectric with infinite thermal contacts at the hot and cold sides, and then analyzed the model based on the energy conservation at each temperature node. The result showed [7], [8] that the thermal and electric co-impedance match leads to maximum power output. This intuitive characteristic allows us to design the fractional area coverage of thermoelectric elements (fill factor) to reduce the mass of the material while keeping the same thermal resistance, hence, the same power output. The TEG modules for integration follow this maximum power output design, so the cost for the additional TEG modules is minimized. The maximum power output per unit area $w_{\max }$ is found as,

$$
w_{\text {max }}=\frac{m Z}{\alpha^{2}(1+m)^{2}} \frac{\beta F}{d_{o p t}}\left(T_{s}-T_{a}\right)^{2}
$$

where, $\alpha$ is a factor determined by the external thermal resistance ratio (see Ref. [8]), which is unity only at a symmetric contact, meaning that the thermal resistances of the hot side and cold side are the same; also $m$ is a ratio of the load resistance to the internal resistance. Note that Eq. (9) is a function of two temperatures at temperature reservoirs, $T_{\mathrm{s}}$ : heat source and $T_{\mathrm{a}}$ : ambient, respectively. These are not the temperatures at the terminals of the thermoelectric element. At the electro-thermal co-optimum, $m=\sqrt{1+Z T}$. At the simplest symmetric contact, the optimum thickness $d_{\mathrm{opt}}[\mathrm{m}]$ is found as $d_{\mathrm{opt}}=m \beta F \sum \psi$, where $\sum \psi$ 
$\left[\left(\mathrm{K}-\mathrm{m}^{2}\right) / \mathrm{W}\right]$ is the sum of the external thermal resistances, including the hot and cold sides. The mass of the thermoelectric element per unit area is linear to $d_{\mathrm{opt}} \mathrm{x} F^{2}$. The best cost performance can be found in the range of 5\% - 10\% depending on the packaging parasitic losses.

\subsection{High temperature TEG and materials}

\section{TEG integrated combustor (First TEG)}

A high temperature TEG device will be highly integrated in the combustor assembly. Two innovative technologies must be contained. One is a high temperature TEG device and the other is a planar fuel injection combustor. There are a few organizations in the United States that conduct technology initiatives, such as the Gas Technology Institute in Illinois, that may be considered as a partner for the development of the technology. Thermoelectric elements that operate at temperatures above $900^{\circ} \mathrm{C}$ have not been actively investigated for commercial or industrial applications. We are looking at such high temperature resistant thermoelectric materials, substrates, and contact (electrode) materials. Silicon germanium ( $\mathrm{SiGe}$, known as a non-toxic material, is the material that has been used in radioisotope thermoelectric generators (RTGs) in space for more than 50 years and has demonstrated a lifetime in excess of 30 years at high temperatures. Recently, the spark plasma sintering (SPS) processed SiGe material has been developed [9] with a ZT of 1.0 for n-type and 0.75 for p-type at $700^{\circ} \mathrm{C}$. Also, 24 element modules with a power output of 3.6 watts have been demonstrated. $\mathrm{Si}_{0.7} \mathrm{Ge}_{0.3}$ can operate at a temperature of about $1000^{\circ} \mathrm{C}$. Nano silicon and $\mathrm{SiGe}$ with lower Ge concentration have a larger bandgap and can be operated at $1200^{\circ} \mathrm{C}$ or higher. It is anticipated that ZT $~ 1.2$ can be achieved at elevated temperatures based on [10]. Other high temperature thermoelectric materials explored for space applications in NASA JPL, where p-type $\mathrm{Yb}_{14} \mathrm{MnSb}_{11}$ and n-type $\mathrm{La}_{3-\mathrm{x}} \mathrm{Te}_{4}$ were reported to show ZT 1 .21.4 at high temperatures over $900{ }^{\circ} \mathrm{C}$ [11]. Thermal expansion is a significant concern due to the large temperature elevation. We have done a mechanical stress analysis considering low fractional area coverage of thermoelectric elements [12], [13]. And we have identified the geometry and designs that relax the stress concentration based on the thermosmechanical properties of the materials stack. Optimization is required to integrate these 
materials with heterogeneous material interfaces.

The combustor design is tuned to a highly exergetic temperature range. Minimization of energy losses and maximization of temperature differences across the TEG device are important. As shown in Fig. 2, the combustion flames (the adiabatic temperature is $1960^{\circ} \mathrm{C}$ ) are located at the thermoelectric elements and arrayed in parallel by planar fuel injection. The air mixture is optimized for the turbine inlet temperature. A majority of compressed and preheated air flows through the colder side. To concentrate the heat flow to the point of the thermoelectric element, lightly pressurized gas impinges toward the TEG module. This allows a higher heat flux to the thermoelectric elements to generate higher power per unit of the cross section area. Further technical details on the impinging heat exchanger are shown in [14].

Fig. 3 shows the cost per unit output power $[\$ / W]$, the output per unit area $\left[\mathrm{W} / \mathrm{m}^{2}\right]$, and the cost per unit area $\left[\$ / \mathrm{m}^{2}\right]$ as a function of the thickness of the thermoelectric element for a given cross section area. The cost $[\$ / \mathrm{W}]$ in particular shows a difference between the thermoelectric material cost only and the module cost. Obviously, the cost impact of the substrate becomes dominant as the thickness of the thermoelectric element becomes smaller. The thinner element allows the heat to go through easily, but the temperature difference is small so the power output is small. In contrast, a thicker element creates a larger temperature difference across the element but disturbs the heat going through. This means that the efficiency is larger but the power output becomes smaller. Therefore, an optimum design exists. In this particular case, the optimum thickness has been found to be around $1 \mathrm{~mm}$ for the $0.32 \mathrm{~mm} \times 0.32 \mathrm{~mm}$ cross section thermoelectric element.

The configuration of the TEG integrated combustor leads to a small amount of heat loss to the ambient through the insulator. The dimension of the burner may be in the range of 0.10 $\mathrm{m} \times 0.10 \mathrm{~m}$, nearly the same as that of a kitchen stove top burner, and the cost may be dramatically reduced with die-casting technology and appliance engineering.

\section{TEG integrated recuperator (Second TEG)}

The recuperator heat exchanger integrates another TEG device illustrated in Fig. 4. To obtain maximum power output, the internal thermal resistance needs to match the 
convective heat transfer. The design challenge is to increase the heat transfer coefficient to overcome the additional thermal resistance of the TEG. The design of this integrated heat exchanger will have a similar structure as the above TEG integrated combustor. Introducing orifices for the hot gas or cooling air at the location of the thermoelectric elements, the heat flux increases by enhanced heat transfer. The thermoelectric material for this mid temperature range has been studied for commercialization; hence, the ZT values of the available materials are in the range of 1.2 and the advanced ones could be $\sim 1.8$. The ZT 2.4 was demonstrated at a narrow temperature range but a lower temperature range based on [15].

\section{TEG embedded flue gas heat recovery (Third TEG)}

Fig. 5 shows a TEG integrated heat exchanger for heat recovery from the flue gas. The configuration is quite similar to that of the recuperator heat exchangers. The flow directions of these two heat exchangers are the same. According to Bell [16], the total heat recovery is higher when both inlets are placed at opposite sides of the heat exchangers. This is due to the mean temperature difference across the thermoelectric element along the flow direction.

\section{Mechanical components}

\section{4-1. Miniature turbo-machinery}

The thermodynamic cycle consists of compressor, turbine, fuel pump, and heat exchangers forming an open cycle of a modified Brayton cycle. In $1 \mathrm{~kW}$ range work output, an automotive turbo-machinery may be the best fit among the existing technologies. Due to the design specification as a turbocharger, the turbine inlet temperature is not as high as we might expect. In Ref.1, it was argued that a $3 \mathrm{~kW}$ turbine with $1050{ }^{\circ} \mathrm{C}$ inlet temperature is possible with the use of selected materials. Due to a very small gas flow rate, the revolution speed of the turbine is very high. The automotive turbocharger will meet this requirement with air bearing technology. Higher isentropic efficiency for the turbine may require significantly high precision manufacturing. For combustion, natural gas should be

pressurized before injection into the combustor, where the mixing air is already pressurized. An inline fuel pump is integrated into the turbo-machinery. 


\subsection{Alternator}

This study does not include a technical consideration of the alternator. By teaming up with an industrial partner, we may be able to develop a high efficiency alternator at a very high turbine rotational speed, which may create a large potential market. In the market, a similar product [17] is already available for $473 \mathrm{~W}$ output at 19,000 rpm with $940 \mathrm{~g}$ of weight designed for Formula One and motorcycle racing vehicle applications. The challenge will be in high volume manufacturability. We assume an ideal (96\% efficiency) alternator at a unit cost of approximately $\$ 600$, while a conventional alternator $(\sim 85 \%)$ costs about $\$ 200$.

\section{Pathway to a cost effective system}

Fig. 6 shows a scheme to approach $40 \%$ efficiency by reducing the power cost. The analysis assumes a raw material cost for the thermoelectric materials of $\$ 500 / \mathrm{kg}$, the substrate for packaging the TEG modules of $\$ 20 / \mathrm{kg}$, the turbo machinery at a cost of $\$ 1,300$ including the turbine and compressor, the pump at a cost of $\$ 200$, and the heat exchangers and packaging enclosure at a cost of $\$ 150$. The design of the TEGs is optimized for maximum power output and yields the most cost effective system. However, it is possible to design the thermoelectric element to be slightly thicker than the optimum so that the efficiency increases by $5-10 \%$ in the TEG part, more than the payback of increasing the material mass.

The starting point of the pathway in Fig. 6 is at $16 \%$ efficiency with power output 397.5 $\mathrm{kW}$ at a cost of $\$ 5$ per watt. With the addition of TEGs at three locations, including the combustor, the recuperator, and the flue gas, the ZT values are 0.8/1.2/1.2, respectively. Then the system could generate $29 \%$ from primary energy (Step 1). Changes in material cost with this step are minimal, while the system power output increases by $319.6 \mathrm{~kW}$ from

three TEGs; hence, the cost ratio $[\$ / W]$ changes mainly from changes in the system efficiency.

In Step 2, considering the improved thermoelectric material properties based on the literature of lab scale research with ZT values 1.2/1.8/1.8 as above, the system efficiency increases to $32 \%$ due to the larger power output $396.7 \mathrm{~kW}$ from the three TEGs. In Step 3, 
we expect the heat exchangers to further advance by a reduction in the thermal resistances in the combustor and an increase in the heat exchanger effectiveness from 0.8 to 0.9 . This makes the Brayton cycle efficiency alone increase by $19.8 \%$ from $15.8 \%$, and the system efficiency will achieve 34.5\%. Finally, in Step 4, we set an aggressive technical target of isentropic efficiencies for the compressor and turbine improving from 0.7 and 0.63 to 0.75 and 0.75 , respectively. These component efficiency targets are achieving a Carnot cycle efficiency of $79 \%$ at the given temperature conditions (see Fig. 1), excluding the external irreversible components. With these given temperature conditions, an ideal recuperated Brayton cycle achieves an isentropic efficiency of $75 \%$ with compression ratio of approximately 2.0. Further reduction of the heat losses through the turbine compartment and the mechanical friction losses will take major roles of the improvement. The change in cost by these technical developments is considered to be minimum since the cost in extremely large scale can be nearly linear to the mass of raw materials such as engines in automotive industry. Taking another example of photo-voltaic, the cost of raw materials $(\$ / \mathrm{kg})$ has an impact on the cost performance $(\$ / W)[18]$ next to the scaling factor and the efficiency improvement of the key material. On the other hand, electro-mechanical efficiency of the alternator would be reduced from 0.96 to 0.9 for a cost effectiveness with assuming a linear relationship of the cost and efficiency for alternators based on [19], where the cost is found as cost $[\$]=3250 *$ (efficiency) - 2520. Hence, the system efficiency will reach $41.7 \%$ with a $\$ 3,000$ material cost for $1 \mathrm{~kW}$ power output.

Since the potential market will be large for consumer applications such as residential homes, the production ramp-up will likely yield a very quick learning curve and lower manufacturing costs. The gas temperature conditions for the TEG embedded heat exchangers remain similar when the above technologies improve. The largest temperature change of $36^{\circ} \mathrm{C}$ is observed at the hot gas inlet of the integrated recuperator, and another change of about $20^{\circ} \mathrm{C}$ is found in the flue gas inlet temperature.

\section{Conclusions}

This paper reports an analytical study of micro-miniature power generators that will 
achieve primary energy efficiency of more than $40 \%$ from natural gas, where the highest efficiency reported for the micro miniature Brayton cycle was only $16 \%$. The investigated model includes thermoelectric modules embedded in a recuperated Brayton cycle at three different locations to recover the heat at different temperature ranges in addition to the power output from an alternator. Each thermoelectric material is different depending on the temperature span, and these narrower temperature ranges help the TEGs to perform the power generation effectively. The mechanical and thermal components of the proposed system are investigated individually. The strategic pathway guides the research and development to achieving the target. The cost performance $[\mathrm{W} / \mathrm{W}]$ is improved essentially by the performance improvement with remaining material mass at large scale manufacturing. The analytical modeling and calculation of the performance shows that the $1 \mathrm{~kW}$ class power output from $2.5 \mathrm{~kW}$ primary energy input (natural gas) is possible.

\section{Acknowledgements}

The authors acknowledge financial support from the National Science Foundation for part of this work.

The authors would like to thank Prof. J.E. Braun and Mr. N.A. James for helping us to identify the efficiency of the recuperative Brayton cycle and for providing their EES model for the calculations. They would also like to thank Prof. Stephen D. Heister and Prof. Xianfan Xu for providing helpful discussions on the high temperature technologies and the waste heat recovery from vehicle engine exhaust.

\section{Nomenclature}

$\begin{array}{ll}d & \text { length, thickness [m] } \\ F & \text { fill factor [-] } \\ T & \text { temperature [K] } \\ W & \text { work [W] }\end{array}$

Greek symbols: 


$\begin{array}{ll}\alpha & \text { thermal resistance ratio [-] } \\ \beta & \text { thermal conductivity [W/(m-K)] } \\ \eta & \text { efficiency [-] }\end{array}$

\section{Suffixes:}

$\begin{array}{ll}\text { A } & \text { alternator } \\ \text { a } & \text { ambient } \\ \text { C } & \text { compressor } \\ \text { FG } & \text { flue gas } \\ \text { g } & \text { chemical (natural gas) } \\ \text { in } & \text { sum of the needed work for the cycle } \\ \text { RC } & \text { recuperater } \\ \text { out } & \text { output } \\ \text { P } & \text { pump } \\ \text { N } & \text { combustion } \\ \text { T } & \text { turbine } \\ \text { TD } & \text { thermodynamic } \\ \text { TEG } & \text { thermoelectric generator } \\ \text { TP } & \text { topping cycle } \\ \text { S } & \text { heat source } \\ \text { sys } & \text { system }\end{array}$

\section{References}

[1] W.P.J. Visser, S. A. Shakariyants, and M. Oostveen, Development of a $3 \mathrm{~kW}$ Microturbine for CHP Applications, J. Enginr. Gas Turbines and Power 133.4 (2011) 042301.

[2] K. Yazawa and A. Shakouri, Optimization of TE Topping Rankine Cycles for Energy Economy, Appl. Energ. vol. 109 (2013) 1-9.

[3] Oakridge National Laboratory, Office of Energy Efficiency and Renewable Energy in the US Department of Energy, Lower-Higher_Heating_Values_for_Various_Fuels.xls, on-line Data Book, Biomass Energy Data Book Appendix-A Conversions, (2011). 
[4] Engineering Equation Solver, http://www.fchart.com/ees/.

[5] S.R. Brown, S.M. Kauzlarich, F. Gascoin, and, G.J. Snyder, Yb14MnSb11: New High Efficiency Thermoelectric Material for Power Generation, Chem. Mater. 18(7) (2006) 18731877.

[6] A.F. May, J.-P. Fleurial, and G.J. Snyder, Thermoelectric performance of lanthanum telluride produced via mechanical alloying, Phys. Rev. B 78 (2008) 125205.

[7] K. Yazawa and A. Shakouri, Optimizing Cost-efficiency Trade-offs in the Design of Thermoelectric Power Generators, Envir. Sci. Techn. Vol. 45 (2011) 7548-7553.

[8] K. Yazawa and A. Shakouri, Optimization of power and efficiency of thermoelectric devices with asymmetric thermal contacts, J. Appl. Phys. Vol.111 (2012) 024509.

[9] K. Romanjek, S. Vesin, L. Aixala, T. Baffie, G. Bernard-Granger, J. Dufourcq, HighPerformance Silicon-Germanium-Based Thermoelectric Modules for Gas Exhaust Energy Scavenging, J. Electr. Mater. Vol. 44(6) (2015) 2192-2202.

[10] X.W. Wang, H. Lee, Y.C. Lan, G.H. Zhu, G. Joshi, D.Z. Wang, J. Yang, A.J. Muto, M.Y. Tang, J. Klatsky, and S. Song, Enhanced thermoelectric figure of merit in nanostructured ntype silicon germanium bulk alloy, Appl. Phys. Lett. 93(19) (2008) 193121.

[11] S. Krishnan, N. K. Karri, P. K. Gogna, J. R. Chase, J.-P. Fleurial, and T. J. Hendricks, J. Electro. Mater, Vol. 41(6) (2012) 1622-1631.

[12] E. Suhir and A. Shakouri, Assembly Bonded at the Ends: Could Thinner and Longer Legs Result in a Lower Thermal Stress in a Thermoelectric Module Design?, J. Appl. Mechan. Vol. 79(6) (2012) 061010.

[13] A. Ziabari, E. Suhir, and A. Shakouri, Minimizing thermally induced interfacial shearing stress in a thermoelectric module with low fractional area coverage, Microelectronics Journal Vol. 45(5) (2014) 547-553.

[14] K. Yazawa, S.D. Heister, and T.S. Fisher, Enhancement and Optimization of Planar Impingement Heat Transfer for Thermoelectric Power Generation, InterPACKICNMM2015 (2015) 48692.

[15] R. Venkatasubramanian, E. Siivola, T. Colpitts, and B. O'Quinn, Thin-film thermoelectric devices with high room-temperature figures of merit, Nature 413 (2001) 597-602

[16] L.E. Bell, Cooling, Heating, Generating Power, and Recovering Waste Heat with 
Thermoelectric Systems, Science, Vol. 321(5895) (2008) 1457-1461.

[17] http://www.magnetimarelli.com/sites/default/files/SF_A55_rev8.0_p.pdf

[18] G. F. Nemet, Beyond the learning curve: factors influencing cost reductions in photovoltaics, Energy Policy, Vol. 34 (2006) 3218-3232.

[19] Advanced Research Projects Agency - Energy (ARPAE), GENerators for Small Electrical and Thermal Systems (GENSETS), Funding Opportunity No. DEFOA0001198, CFDA Number 81.135 (2014) 17. 


\section{FIGURES and TABLES}

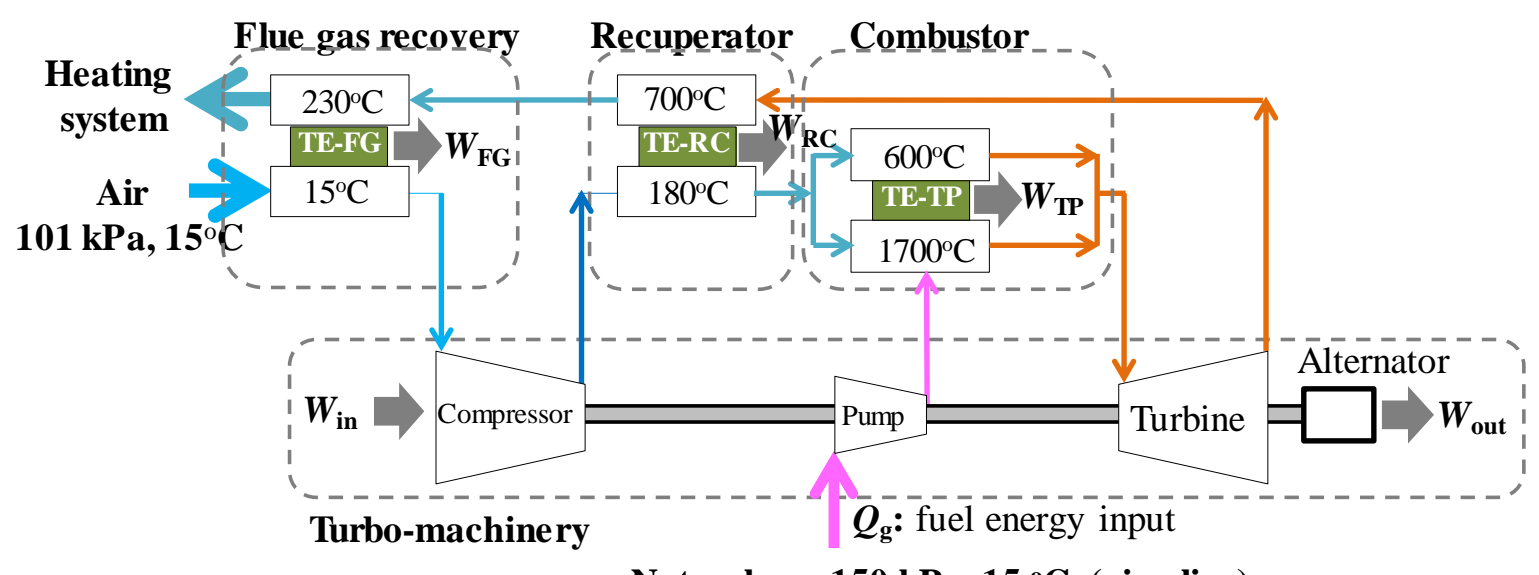

Natural gas $150 \mathrm{kPa}, 15^{\circ} \mathrm{C}$ (pipe line)

Figure 1: System concept diagram. The values in the heat exchanger boxes show typical inlet temperatures. The conditions are the following. Turbine inlet temperature assumes up to $1100{ }^{\circ} \mathrm{C}$. Heat exchanger effectiveness without TEG modules assumes 0.8 . The mass flow rate of natural gas assumes $0.456 \mathrm{~g} / \mathrm{s}, 101 \mathrm{kPa}$ to compensate for the $25 \mathrm{~kW}$ of chemical energy input. The isentropic efficiency of the compressor and turbine are 0.7 and 0.63, respectively. The alternator electro-mechanical efficiency is 0.96 .

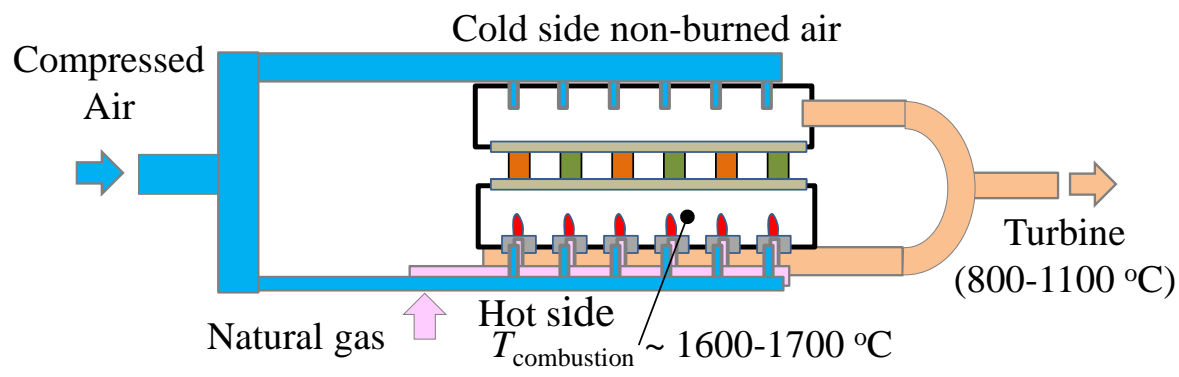

Figure 2: TEG integrated combustor concept diagram with typical temperature values. The flow rates in the branches of hot and cold assume an appropriate design to provide the desired turbine inlet temperature. The conditions are the same as in Fig. 1. 

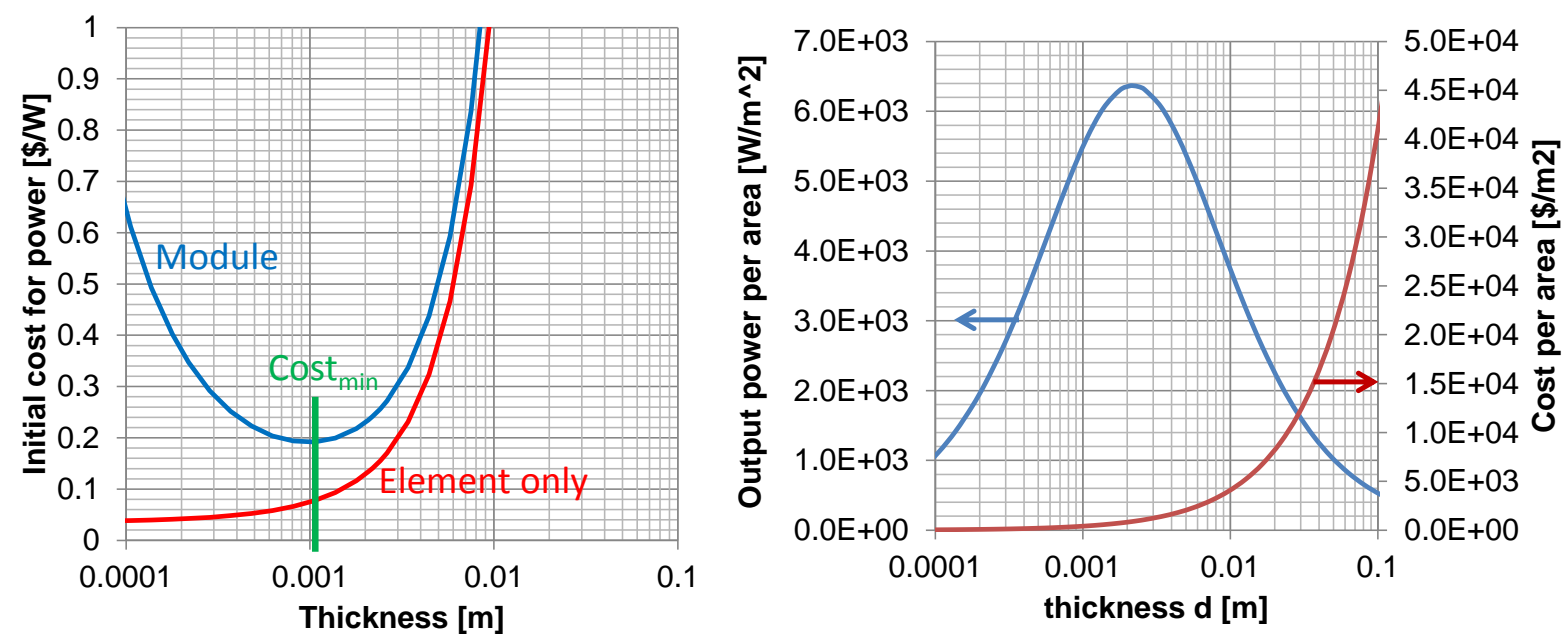

Figure 3: TEG embedded in heat exchanger cost (left), power output, and cost per area (right) as the functions of thickness for the given cross section area, assuming ZT $=1.2$ and $\$ 500 / \mathrm{kg}$ for the thermoelectric material and $\$ 20 / \mathrm{kg}$ for the substrate material for TEG modules.

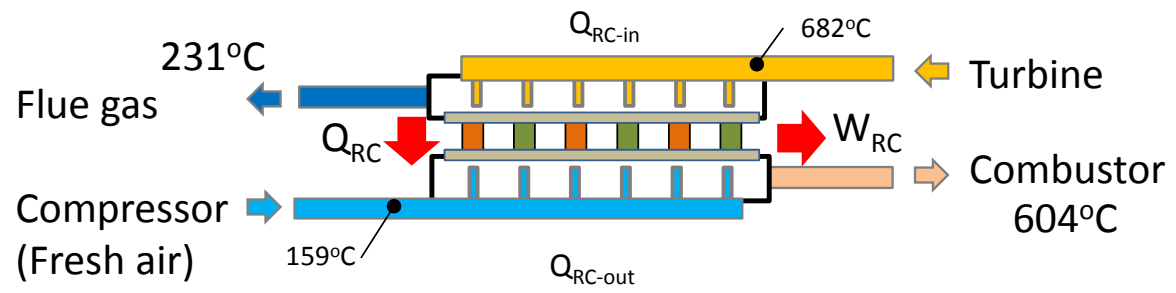

Figure 4: TEG embedded recuperator concept diagram with typical temperature values. The conditions are the same as in Fig. 1.

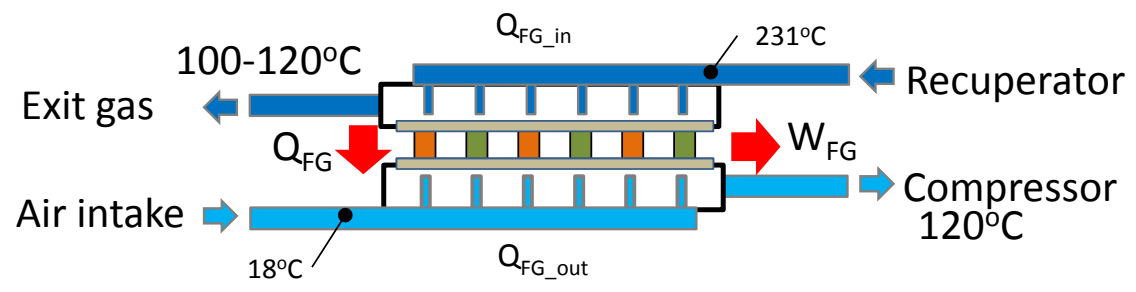

Figure 5: TEG embedded flue gas waste heat recovery concept diagram. The conditions are the same as in Fig. 1. 


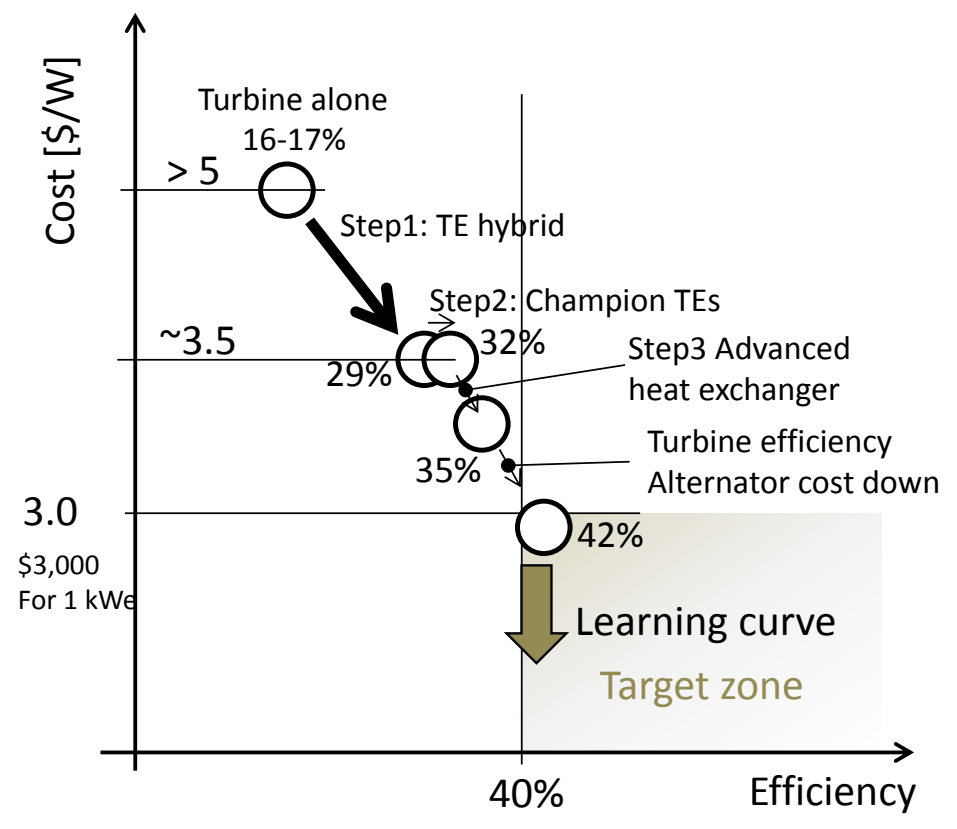

Figure 6: Initial cost $[\$ / \mathrm{W}]$ and efficiency of the system.

Table 1: Thermoelectric materials

\begin{tabular}{|c|c|c|c|}
\hline ZT value & TEG-TP & TEG-RC & TEG-FG \\
\hline Case 1 & 0.8 & 1.2 & 1.2 \\
\hline Case 2 & 1.0 & 1.8 & 1.8 \\
\hline
\end{tabular}


Table 2 Efficiencies

\begin{tabular}{|l|r|r|r|r|r|}
\hline & \multicolumn{1}{|c|}{ Step0 } & \multicolumn{1}{c|}{ Step1 } & \multicolumn{1}{c|}{ Step2 } & \multicolumn{1}{c|}{ Step3 } & \multicolumn{1}{c|}{ Step4 } \\
\hline Brayton cycle & $17.3 \%$ & $15.9 \%$ & $15.8 \%$ & $19.3 \%$ & $28.7 \%$ \\
\hline TEG-TP & - & $2.9 \%$ & $3.5 \%$ & $3.5 \%$ & $3.5 \%$ \\
\hline TEG-RC & - & $6.3 \%$ & $8.0 \%$ & $7.8 \%$ & $6.2 \%$ \\
\hline TEG-FG & - & $3.6 \%$ & $4.5 \%$ & $3.9 \%$ & $3.3 \%$ \\
\hline & $17.3 \%$ & $28.7 \%$ & $31.7 \%$ & $34.5 \%$ & $41.7 \%$ \\
\hline
\end{tabular}

